\title{
Alcohol and Self-Evaluation: Is a Social Cognition Approach Beneficial?
}

\section{Citation}

Banaji, Mahzarin R., and Claude M. Steele. 1989. Alcohol and self-evaluation: Is a social cognition approach beneficial? Social Cognition 7, no. 2: 137-151. doi:10.1521/soco.1989.7.2.137. Reprinted with permission of The Guilford Press.

\section{Published Version}

doi:10.1521/soco.1989.7.2.137

\section{Permanent link}

http://nrs.harvard.edu/urn-3:HUL.InstRepos:29429752

\section{Terms of Use}

This article was downloaded from Harvard University's DASH repository, and is made available under the terms and conditions applicable to Other Posted Material, as set forth at http:// nrs.harvard.edu/urn-3:HUL.InstRepos:dash.current.terms-of-use\#LAA

\section{Share Your Story}

The Harvard community has made this article openly available.

Please share how this access benefits you. Submit a story.

\section{Accessibility}




\section{ALCOHOL AND SELF-EVALUATION: IS A SOCIAL COGNITION APPROACH BENEFICIAL?}

MAHZARIN R. BANAII

Yale University

CLAUDE M. STEELE

University of Michigan

Based on psychosocial models, a view of alcohol use and addiction as resulting from a habitual maladaptive means of coping with stress has recently emerged. In this article, we present some critical experiments documenting the effects of alcohol on stress, self-awareness, and self-evaluation as exemplars of a social cognition approach to the study of alcohol and stress. We assert that a social cognition approach is a valuable theoretical framework and document the benefits for investigations of alcohol's impact on social, psychological, and health-related behaviors.

Alcohol use and alcoholism constitute a major national health problem. A study by the National Institute of Medicine shows that since 1960 alcohol consumption has risen by more than $30 \%$, and in 1983 the congressional Office of Technology Assessment estimated the cost of alcoholism and alcohol abuse to be $\$ 120$ billion. In the United States, $10 \%$ of deaths every year are alcohol-related, $33 \%$ of occupants of hospitals are patients with alcohol-related problems, and $12 \%$ of the total national health budget is spent on patients with alcohol abuse problems (West, 1984).

Although it is clear that a problem as complex as alcohol addiction requires a diversity of theoretical and methodological approaches, the dominant approach is one of understanding alcohol use and addiction as a biologically based disorder with relatively little attention to psy-

We thank Leslie Clark and three anonymous reviewers for comments on a previous draft of this manuscript. This research was supported by NIAAA grant \# AA05712-05 to Claude Steele and an NIAAA post-doctoral fellowship to Mahzanin Banaji at University of Washington. Address correspondence to Mahzarin R. Banaii, Department of Psychology, Yale University, P.O. Box 11A, Yale Station, New Haven, CT 06520-7447. 
chological factors. In contrast to this view, psychosocial models of cholion of physiological and psychological factors in addiction, and emphasize in particular the ple of beliefs, expectancies, and attributions as important sources of data to understand addiction as a way of coping with stress. More recently, a stronger emphasis than before has been placed on theoretical models that view alcohol use and addiction as resulting from habitual maladaptive means of coping with stress (Marlatt, 1985).

Although the relatively recent attention to psychosocial factors is viewed with optimism, it should be pointed out that the focus has been on treatment and prevention issues, and basic research on the social psychological study of the antecedent conditions and consequences of alcohol use and addiction remain relatively unexplored.

A growing interest in health psychology (Baum, Taylor, \& Singer, 1984. Sanders \& Suls, 1982), an unprecedented attention to social 1984, Sand alcohol use (see Marlatt, 1985; Tabakoff, Sutker, \& Randall, 1983), and the concurrent publication of studies of alcohol and social behavior in social psychology journals (Hull \& Young, 1983; Steele \& Southwick, 1985; Steele, Critchlow, \& Liu, 1985) are encouraging advances in the context of which we present this discussion.

First, we briefly present some theoretical constructs and empirical findings in three relevant areas: alcohol's impact on stress, alcohol's effects on cognition, and alcohol's effects on self-awareness. Next, we discuss a study conducted to understand alcohol's effects on selfevaluation. Finally, we discuss the benefit of a social cognition approach to the study of alcohol and social behavior and health and propose a direction in which research on alcohol can be furthered by the use of a mentalistic approach to the study of behaviors influenced by alcohol intoxication. In doing so, we believe, alcohol research stands to gain by the introduction of new theoretical models as well as a diversity of methodologies, and the social cognition approach is enriched by the inclusion of an important domain of alcohol-related health behaviors.

\section{ALCOHOL'S EFFECTS ON STRESS}

An influential behavioral conceptualization of alcohol use has been the tension-reduction hypothesis (Conger, 1956). According to this model, reinforcement for the drinking response is attributed to alcohol's ability to relieve stress and tension. Addiction results if drinking becomes excessive in response to stress, following which tolerance to alcohol develops, so greater amounts of alcohol are required to produce the same stress-reducing benefits.
As tests of the model began to accumulate, however, it appeared that alcohol use in stress-inducing situations was more complex than originally advocated (cf. Cappell \& Herman, 1972; Marlatt, 1976). Sometimes alcohol appeared to reduce stress (Levenson, Sher, Grossman, Newman, \& Newlin, 1980; Sher \& Levenson, 1982), sometimes it produced no effect (Thayer \& Curtis, 1984; Wilson \& Abrams, 1977). and at other times it increased reactions to stress (Abrams \& Wilson, 1979; Keane \& Lisman, 1980). It is now clear that alcohol has no direct, tension-reducing effect that generalizes across variables of stress, individual differences, and situations.

Most recently, Steele \& Josephs (1988) addressed the issue of alcohol's tension-reducing effects by proposing a more complex model, in which alcohol, in combination with a distractor task (but not otherwise), produces stress-reducing effects. Their prediction was based on the hypothesis that under conditions of alcohol intoxication the performance of an activity places greater demands on the cognitive resources that are available. This results in reducing processing capacity in general, and hence, reducing the processing capacity for stressful cognitions as well.

In their research, sober and intoxicated subjects were led to believe that they would deliver a speech on the stressful topic "What I dislike most about my body and physical appearance." Subsequently, half of the subjects in the alcohol and placebo conditions were asked to perform a distractor task, and the other half performed no activity, while several measures of stress were obtained. According to their prediction, subjects in the alcohol-alone condition reported the greatest amount of stress, and subjects in the alcohol-plus-activity condition reported the lowest amount of stress. An important aspect of this research is the role of the distractor activity that mediates the alcohol-stress relationship. Alcohol, it appears, reduces stress not through any direct anxiety-reducing effect but through the reduction of processing capacity (provided by the distractor task). By focusing on the role of cognitive impairment and attention allocation, Steele and Josephs (1988) were able to provide evidence for a potentially important variable that mediates alcohol's anxiety-reducing effects.

\section{ALCOHOL'S EFFECTS ON COGNITIVE PROCESSES}

Much of the research on alcohol's effects on cognitive processes has been directed at documenting the deficits produced by alcohol on attention, memory, judgment, and the like. Although this research is important in its own right, findings from this area have been ad- 
ditionally useful in providing information about the mechanisms that underlie alcohol's impact on variables such as stress and coping. An example of this contribution is Steele and Josephs' (1988) research discussed earlier, Hull and his colleagues' (Hull, Levenson, Young, \& Sher, 1983; Hull \& Young, 1983; Hull, Young \& Swank, 1981) research on alcohol's effect on self-awareness, and Banaji and Steele's (1988) research on alcohol and self-evaluation.

Unlike the research findings on alcohol's impact on stress, the findings in this domain are consistent: Alcohol affects the ability to learn new information (Birnbaum \& Parker, 1977; Miller, Adesso, Fleming, Gino, \& Lauerman, 1978), the ability to retrieve semantic information (Nelson, McSpadden, Fromme, \& Marlatt, 1986), the ability to use several cues at the same time (Medina, 1970; Moskowitz \& Depry, 1968), the ability to use active and systematic encoding strategies (Rosen \& Lee, 1976), the ability to encode large numbers of situational cues (Washburne, 1956), and the ability to engage in effortful control processing (Schneider, Dumais, \& Shiffrin, 1984).

Although a substantial body of work exists on the effects of alcohol on cognitive processes in general, and particularly on memory, few investigations have used these findings to develop and test hypotheses about their mediating role in the alcohol and social behavior relationship. The purpose of this article is to emphasize that a social cognition approach facilitates such explorations, and the merits of this approach are discussed in a later section.

\section{ALCOHOL'S EFFECTS ON SELF-AWARENESS}

Although a commonly held view of alcohol use is that intoxication makes the consumer "forget the unpleasant," there are few experimental treatments that have demonstrated any consistent effects or offered satisfactory explanations of the actual mediators of the effect.

One line of research, pursued by Hull and his colleagues (1981, 1983) tested the idea that alcohol decreases self-awareness by inhibiting higher-order cognitive processes about oneself and, as a result, produces effects that are the opposite of those occurring under heightened selfawareness. One such effect is to decrease negative self-evaluation following failure, which may account for the reinforcing value of alcohol consumption (Hull \& Young, 1983).

Hull et al. (1983) demonstrated that alcohol consumption (but not an expectancy of alcohol consumption) decreased self-awareness as measured by reduced frequency of self-focused statements and an increase in other-focused or unfocused statements. They also showed that under the influence of alcohol, subjects who were dispositionally high in self-consciousness (and showed better memory for self-relevant than for nonrelevant words) showed greater memory deficits for selfrelevant words compared to low self-conscious subjects.

Finally, Hull, Young, \& Swank (1981), in a longitudinal study, showed that alcoholic relapse following detoxification was highest among highly self-conscious subjects who had experienced predominantly negative life events, compared to those who had experienced positive life events as well as to subjects with low self-consciousness. Although this research has been a contribution to the literature on alcohol's stress-reducing effects, criticisms of Hull's research have included failures to replicate some effects as well as a failure to account for evidence of expectancy effects on behavior (Wilson, 1983).

Our own efforts were guided more by an interest in alcohol's effects on self-evaluation processes in general rather than by an interest in a single individual difference variable such as self-consciousness. In the next section, we describe research conducted by Banaji \& Steele (1988) to explore the effects of alcohol on self-evaluation.

\section{ALCOHOL AND SELF-EVALUATION}

The theoretical basis of this research was derived from two sources: Steele and Southwick's (1985) proposal of a conflict model of alcohol's effects on social behavior, and a variety of motivational accounts of the self (cf. Tesser \& Campbell, 1983; Wicklund \& Gollwitzer, 1982). We discuss each of these briefly before presenting the research itself.

A Conflict Model of Alcohol and Social Behavior. Steele \& Southwick (1985) noted that the literature on alcohol's effects on social behaviors (aggression, assertiveness, risk taking, sexual interest, etc.) did not show consistent results. As with the literature on alcohol and stress, sometimes alcohol increased the extremity of responses and at other times produced no effect. They proposed that alcohol's effect depended on the degree to which a specific response was subject to the simultaneous arousal of incompatible response tendencies, or what they called "response conflict."

Specifically, they proposed that alcohol should make a social response more extreme if that response was normally under strong inhibitory conflict, that is, influenced by instigating and inhibiting stimuli. On the other hand, alcohol and placebo groups should not differ under conditions of weak inhibitory conflict. Predictions of such interaction effects are an important departure from pharmacological models of the effects of alcohol on stress and coping. Introducing 
ideas of conflict, attention allocation, and the like have allowed investigators to derive more complex models of alcohol and social behavior compared to relatively simplistic notions such as the previously popular tension-reduction hypothesis.

In a meta-analysis of studies using alcohol as the independent variable and a wide variety of social behaviors as the dependent variable, they found that alcohol intoxication resulted in more extreme behaviors but only when the behavior was judged to be under strong inhibitory conflict. On the contrary, alcohol did not produce changes when the behavior was under weak response conflict. In research undertaken to test this model, Steele et al. (1985) showed that helping behavior was increased under alcohol intoxication but only when the helping response was under strong inhibitory conflict (i.e., the task was boring but the experimenter asked for more help). Although an assumption of the model was that alcohol's effects were due to its impact on perceptual and cognitive functioning, no direct evidence for it was obtained. In later studies (Banaji \& Steele, 1988), some evidence for the mechanism of alcohol's effect was obtained.

Motivational Accounts of the Self. We were interested in applying ideas of inhibitory response conflict to a domain where conditions of high and low cognitive conflict could be meaningfully manipulated and a measure of the cognitive mechanisms underlying alcohol's effect could be collected. The domain we chose was self-evaluation, and in this regard, several motivational accounts of the self-concept provided a useful framework.

Motivational theories of the self have often made self-evaluation processes the target of study. Tesser and Campbell's (1983) self-evaluation maintenance model is based on the assumption that people are motivated to maintain a positive self-evaluation and that they will behave in ways that allow such evaluations to occur. Duval and Wicklund's (1972) theory of objective self-awareness states that increased self-focused attention increases discrepancies between one's concept of real self and standards of correctness, which, in turn, motivate a reduction in discrepancy. Wicklund and Gollwitzer (1982) point out that falling short of a standard is experienced as a negative self-evaluation leading to a state of self-reflection that motivates seeking a symbol of "self-completion." Breckler and Greenwald's (1986) proposal for studying motivational facets of the self is based on the belief that "self-evaluation is a potent energizer of human activity." Higgins's (1987) self-discrepancy theory offers a specific proposal of differences in affective outcome as a function of differing self-discrepancies. Most recently, Taylor and Brown (1988) have claimed that a positive sense of self, even if inaccurate, may be a valuable resource in maintaining mental health.

We proposed a model for understanding alcohol's effects on selfevaluation based on the following line of reasoning: If individuals are motivated to maintain positive self-evaluations, and alcohol impairs effortful, controlled processing, then self-evaluations under alcohol intoxication should reflect the "myopic" processing attributed to alcohol in general. Based, in general, on previous proposals of a dynamic conceptualization of the self and specifically on Steele and Southwick's (1985) conflict model, we derive hypotheses to study alcohol's effects on self-evaluation. Alcohol should enhance one's view of real self if two conditions are met:

1. Dimensions that are the focus of self-evaluation are important to the individual, that is, central to the self-concept. As James (1890) pointed out, " $I$, who for the time have staked my all on being a psychologist, am mortified if others know much more psychology than I. But I am contented to wallow in the grossest ignorance of Greek. My deficiencies there give me no sense of personal humiliation at all" (p. 310). The dimensions that subjects rate as important to them should serve as potential sources of conflict if a second condition is met.

2. A discrepancy between one's real and ideal self exists. If ideal self and real self "match up" (irrespective of the importance of the domain), no conflict should result. On the other hand, if one's real self falls short of standards set by one's vision of an ideal self, a conflict needing resolution will result.

Thus, we hypothesized that alcohol would induce a change in prior ratings of one's real self to approximate ratings of ideal self if the dimension being judged was important to the individual and if a discrepancy between ideal and real self existed. On the other hand, changes in ratings of real self after alcohol would be insignificant if the trait dimensions were unimportant to the subject and no discrepancy between real and ideal self existed. Further, no significant changes should occur in a placebo condition.

Several experiments have been conducted to test these hypotheses. We present an overview of the procedure used and the findings obtained in a typical study. We then present an experiment directed toward obtaining evidence for the cognitive mechanism that mediates the effect of alcohol on self-evaluation. Subjects are tested in two sessions, during each of which they rate themselves on several dimensions. In the first session, subjects are given three booklets, each consisting of bipolar scales anchored by trait adjectives, such as Intelligent-Unintelligent, Friendly-Unfriendly, Well-read-Poorly read, Independent- 
Dependent, Sincere-Insincere, and so on. For each set of trait words, subjects are asked to rate (1) their real self, (2) their ideal self, and (3) the importance of the dimension to them. After performing these ratings, subjects sign up to participate in the actual experiment 2 to 3 days later.

During the experimental session, subjects were administered either an alcohol or a placebo drink. In the alcohol condition, 80-proof vodka mixed with tonic water was consumed to reach a blood alcohol level of 0.08 . To hold expectancy of alcohol constant, subjects in the placebo condition believed they had received an alcoholic drink. After absorption, subjects were given three rating scales that were identical to the ones they had previously completed, consisting of measures of real self, ideal self, and importance of the dimension.

The dependent variable in these experiments was the change in ratings of real self obtained prior to versus after alcohol or placebo consumption. From each subject's data, subsets of items were chosen to represent the high-conflict and low-conflict items that then constituted each subject's final scores. To compute the composite high-conflict score, the ten dimensions receiving the highest importance ratings were chosen. For each of these items, the discrepancy between real self and ideal self was calculated by subtracting the real self rating from the ideal self rating. From a product score of importance by discrepancy, the mean of the five traits with the highest score was computed. To compute the equivalent low-conflict score, the same procedure was followed, with the exception that (1) the ten traits rated as least important (rather than most important) were chosen, and (2) from the final importance-by-discrepancy product score, the mean of the five traits with scores closest to zero (rather than the highest score) was computed. Thus, each score combined information about importance of the dimension and discrepancy between ideal and real self.

The data of the first study supported the hypothesis that alcohol would induce a change in ratings of real self on high-conflict items but not in any of the other conditions of the $2 \times 2$ design. Mean change in rating of real self in the alcohol/high-conflict condition was significantly different from zero $(M=1.99)$, as well as from each of the other three conditions. In contrast, mean changes in ratings of real self in the placebo condition for high-conflict items $(M=0.30)$ and low-conflict items $(M=0.38)$ were not significantly different from zero or from each other. Similarly, change in the alcohol/low-conflict condition was not significantly different from zero $(X=-.43$ ). (In a subsequent study, we found that the "self-inflation effect" obtained in the alcohol/high-conflict condition was not a function of feelings of positive affect induced by alcohol.)

What is the mechanism by which alcohol produces self-inflation on dimensions of high conflict? One hypothesis is a variant of the cognitive impairment interpretation; that is, self-inflation occurs as a result of narrowed focus on a subset of self-knowledge from the pool of information that is available under conditions of sober selfevaluation.

Based on various motivational accounts of the self, we assume that, when sober, there is a tendency to present oneself in a positive light, both to others as well as to oneself (Breckler \& Greenwald, 1986; Taylor \& Brown, 1988). However, it is also adaptive to think realistically about one's shortcomings in order to succeed, and in fact, several theories have claimed this to be a central ingredient of mental health (e.g., Jahoda, 1958). For example, it may be necessary for $A$ to realize that in spite of her hard work in art courses, she consistently performs poorly. The inference "My artistic skills are mediocre" is an important self-evaluation, since it then allows $A$ to think about alternative modes of self-expression where success is more likely. So in the course of daily life, although a bias to think of oneself in a positive light operates, realistic appraisals are also necessary and are routinely performed.

A second assumption is that under the reduced processing conditions of alcohol intoxication, attention is focused on information that is most salient and easily available. Self-enhancing information receives greater attention not because alcohol predisposes the individual to selectively access positive items of self-knowledge; rather, alcohol's general information-processing deficit creates a situation in which positive self-knowledge gains precedence because of its salience. $\mathrm{Ob}$ viously, this prediction extends to those individuals who, in general, have a sense of positive well-being. It is conceivable that depressed individuals, who are predisposed to negative, if perhaps more accurate, self-perceptions would not show the same benefit under alcohol intoxication because negative self-knowledge would be more salient for these individuals.

If the self-inflation effect obtained in the previous studies was a function of subjects' attending to predominantly self-enhancing information on which their judgment was based, then inducing subjects to access negative self-knowledge relevant to the dimension being judged should eliminate the self-inflation effect. In this study, we sought to create interference in spontaneously occurring thoughts (supposedly positive in nature) at the time of self-evaluation and instead manipulated the production of negative, discrepancy-relevant information from subjects. If disruption of spontaneously occurring 
thoughts change self-evaluations such that no self-inflation effect is obtained (in the alcohol/high-conflict condition), then the cognitive impairment hypothesis would be supported.

In the experiment, subjects filled out the three rating scales (real self, ideal self, and importance of dimension) during the first session. During the experimental session, they were assigned to an alcohol or placebo condition, following which they were assigned to an anagram task condition or a discrepancy-reasoning task condition. To perform each of these tasks, subjects were given only the ten high-conflict and ten low-conflict dimensions, selected in the previously established manner.

In the anagram task, subjects were asked to form as many words as possible using the letters available in the trait word labels of the dimension. In the discrepancy-reasoning task, subjects were asked to think about reasons for the discrepancy between their real and ideal selves. For instance, on the dimension of intelligence, a subject might say, "I work harder than my friends, but my grades consistently are poorer." Subjects were informed to write about any thought, feeling, or action they might use in judging why their real self was ranked lower than their ideal self. After performing either task, subjects made the critical judgment of rating their real self on that dimension.

Results from this experiment support the notion that under alcohol intoxication, a self-inflation effect is obtained if subjects' thoughts prior to self-evaluation are not disrupted. If an interference task is performed in which negative self-evaluations are generated, subjects do not show the self-inflation benefit.

First, as expected, data from the anagram task follow the pattern of previous experiments. As Table 1 shows, subjects in the alcohol high-conflict condition show a self-inflation effect, but not subjects in the other three conditions: alcohol/ow-conflict and the two placebo

TABLE 1

Mean Change in Ratings of Real Self for Anagram and Discrepancy-Reasoning Task Conditions, under Alcohol and Placebo Conditions for High-Conflict and Low-Conflict Items

\begin{tabular}{lccccc} 
& \multicolumn{2}{c}{ ANAGRAM TASK } & & \multicolumn{2}{c}{$\begin{array}{c}\text { DISCREPANCY } \\
\text { REASONING TASK }\end{array}$} \\
\cline { 2 - 6 } & $\begin{array}{c}\text { ALCOHOL } \\
(n=10)\end{array}$ & $\begin{array}{c}\text { PLACEBO } \\
(n=12)\end{array}$ & $\begin{array}{c}\text { ALCOHOL } \\
(n=14)\end{array}$ & $\begin{array}{c}\text { PLACEBO } \\
(n=13)\end{array}$ \\
\hline High-conflict items & 4.30 & .25 & -.60 & .58 \\
Low-conflict items & -.34 & -1.27 & -2.11 & -2.58 \\
\hline
\end{tabular}

conditions. In the discrepancy-reasoning condition, the pattern of data is quite different. These data show that in the presence of thoughts about the reasons for ideal-real discrepancy, the self-inflation effect was eliminated in the alcohol/high-conflict condition. On the other hand, the anagram task, which did not interfere with spontaneously generated thoughts prior to self-evaluation, replicated the previously obtained self-inflation effect. ${ }^{1}$

Although we did not manipulate stress directly, as in the Steele and Josephs (1988) study, this research has implications for understanding alcohol use and its impact on stress and coping. It suggests that alcohol, through its myopia-producing mechanism, provides protection from stress caused by accurate perceptions of oneself. And it is the same benefit that creates the illusion of well-being that may also contribute to the reinforcing value of alcohol that ultimately leads to addiction. Although several aspects of the current proposal need further evidence, we discuss it here as an example of a social cognition approach to the study of alcohol's role in stress and coping.

\section{WHAT CAN A SOCIAL COGNITION APPROACH DO?}

The field of social cognition, according to one advocate, is "concerned with determining the nature of social knowledge and with specifying the cognitive processes that mediate social behavior" (Ostrom, 1984, p. 28). Such an approach will allow investigators to study traditional problems of alcohol and mental health and, concurrently, permit the researcher to ask questions about the specific mechanisms underlying alcohol intoxication that contribute to its reinforcing value.

1. Two points need to be made about these data. First, it may be argued that if salient cognitions are critical in self-evaluations under intoxication, then providing subjects with the task of generating negative self-evaluations should lead to change in the opposite direction (i.e., away from ideal self) in the alcohol/high-conflict condition. Instead, we found no change in that condition or the placebo/high-conflict condition It is possible that the task used in this study (i.e., generating a negative, discrepancyreasoning thought or feeling) was not sufficiently powerful to create a negative selfevaluation. Future research using a stronger manipulation will provide the necessary test.

Second, on the low-conflict items (in both alcohol and placebo conditions), mean rating of real self changed significantly in the negative direction. It is possible that this effect is due to the low-conflict nature of the trait dimensions. When subjects generated negative thoughts on dimensions that do not produce conflict, they may have been less inclined to defend against those thoughts, thus showing the effect of salient thoughts on self-evaluations in both alcohol and placebo conditions. This effect needs to be replicated before further interpretations are offered 
There are several specific advantages to employing a social cognition approach. First, since social cognition is not a remote field of inquiry but rather an approach that is used in social, cognitive, developmental, personality, clinical, community, and, most recently, health psychology, it is especially appealing in research on alcohol use, with its diverse etiology and need for a multidisciplinary perspective. Thus, findings about alcohol-related processes from clinical, cognitive, personality, and social psychology can be connected by a focus on cognitive processes.

Second, in social psychology, a social cognition approach has allowed previously ignored constructs like affect, emotion, and motivation that traditionally received isolated treatment to be integrated with a study of cognitive mechanisms. This is particularly attractive in the study of alcohol-related behaviors where motivational and cognitive causes and consequences have always been acknowledged but have lacked a framework for conceptualizing and a methodology for testing theories. ${ }^{2}$

Third, a social cognition approach affords an alternative to univariate theories of alcohol-induced behaviors by its amenability to a converging operations approach. Several measures, like recall and reaction time, unconstrained cognitive responses, attributions, and affective responses can be collected and validity established through their convergence.

Fourth, a disappointing aspect of alcohol research has been the pervasiveness of inconsistent findings. Alcohol has sometimes shown increases in a certain behavior but not in related behaviors (cf. Steele \& Southwick, 1985), or produced opposite effects (increases and decreases in stress and anxiety) (cf. Steele \& Josephs, 1988). As other researchers have noted (Wilson, Perold, \& Abrams, 1981), studying the specific conditions under which alcohol produces its effects is necessary if we are to understand the workings of a complex substance. By focusing on information-processing variables, more complex models of alcohol use and addiction can be constructed in which interaction between social variables and dosage rather than main effect predictions (such as, alcohol reduces tension and stress) can be explored.

Finally, a social cognition approach will allow explanations of alcohol's effects at a level of individual mental functioning in addition to traditionally proposed global explanations, such as those based on

2. It should be acknowledged here that investigators like Marlatt (1976) and Wilson (1978) have for the last decade stressed the importance of cognitive mediators in alcoholrelated behaviors and have done so in their own work in the context of social learning theory. social learning theory (Bandura, 1977). In particular, this approach will contribute to a better understanding of the role of alcohol use in stress reduction and will eventually contribute to an understanding of psychosocial factors in addiction.

In this article, we review alcohol's known effects on stress, cognition, and self-awareness. Based on the literature, we proposed a model of alcohol's effect on self-evaluation and discussed preliminary evidence in support of it. We conclude by stating that a focus on the effects of alcohol on cognitive processes like memory, attention, judgments of time, frequency, affect, and the like will facilitate the development of more sophisticated models of alcohol's effects on social behavior. Investigators interested in the influence of alcohol on social behaviors, the cognitive and affective variables that mediate this relationship, and isolating the mechanisms by which alcohol provides its reinforcing effects will find a social cognition approach valuable.

\section{REFERENCES}

Abrams, D. B., \& Wilson, T. G. (1979). Effects of alcohol on social anxiety: Cognitive versus physiological processes. Journal of Abnormal Psychology, 88, 161-173.

Banaji, M. R., \& Steele, C. M. (1988). Alcohol and self-inflation. Unpublished manuscript, Yale University, New Haven, CT.

Bandura, A. (1977). Social learning theory. Englewood-Cliffs, NJ: Prentice-Hall.

Baum, A., Taylor, S. E., \& Singer, J. E. (1984). Handbook of psychology and health (Vol. 4). Hillsdale, NJ: Erlbaum.

Birnbaum, I. M., Johnson, M. K., Hartley, J. T., \& Taylor, T. H. (1980). Alcohol and elaborate schemes for sentences. Journal of Experimental Psychology: Human Learning and Memory, 66, 293-300.

Birnbaum, I. M., \& Parker, E. S. (1977). Acute effects of alcohol on storage and retrieval. In I. M. Birnbaum, \& E. S. Parker (Eds.), Alcohol and Human Memory. Hillsdale, NJ: Erlbaum.

Breckler, S. J., \& Greenwald, A. G. (1986). Motivational facets of the self. In R. M Sorrentino \& E. T. Higgins (Eds.), Motivation and Cognition. New York: Guilford Press.

Cappell, H., \& Herman, C. P. (1972). Alcohol and tension reduction: A review. Quarterly Journal of Studies on Alcohol, 33, 33-64.

Conger, J. J. (1956). Reinforcement theory and the dynamics of alcoholism. Quarterly Journal of Studies on Alcohol, 17, 296-305.

Duval, S., \& Wicklund, R. A. (1972). A theory of objective self-awareness. New York: Academic Press.

Higgins, E. T. (1987). Self-discrepancy: A theory relating self and affect. Psychological Review, 94, 319-340.

Hull, J. G., Levenson, R. W., Young, R. D. \& Sher, K. J. (1983). Self-awareness reducing effects of alcohol consumption. Journal of Personality and Social Psychology, 44, 461-474.

Hull, J. G. \& Young, R. D. (1983). Self-consciousness, self-esteem, and success-failure 
as determinants of alcohol consumption in male social drinkers. Journal of Personality and Social Psychology, 44, 1097-1109.

Hull, J. G., Young, R. D., \& Swank, L. E. (1981). Self-consciousness, social anxiety, and relapse following detoxification. (Unpublished manuscript).

lahoda, M. (1958). Current concepts of positize mental health. New York: Basic Books. James, W. (1890/1950). The principles of psychology (Vol. 1). New York: Dover.

Keane, T. M., \& Lisman, S. A. (1980). Alcohol and social anxiety in males: Behavioral, cognitive, and physiological effects. Journal of Abnormal Psychology, 89, 213-223.

Levenson, R. W., Sher, K. J., Grossman, L. M., Newman, J., \& Newlin, D. B. (1980). Alcohol and stress response dampening: Pharmacological effects, expectancy, and tension reduction. Journal of Abnormal Psychology, 89, 528-538.

Marlatt, G. A. (1976). Alcohol, stress and cognitive control. In I. G. Sarason \& C. D. Speilberger (Eds.), Stress and Anxiety (Vol. 3). Washington, DC: Hemisphere

Marlatt, G. A. (1985). Coping and substance abuse: Implications for research prevention and treatment. In S. Shiffman \& P. A. Will (Eds.), Coping and substance abuse (pP. 367-386). New York: Academic Press.

Medina, E. L. (1970). The role of the alcoholic in accidents and violence. In R. E. Popham (Ed.). Alcohol and Alcoholism. Toronto: University of Toronto Press.

Miller, M. E., Adesso, V. J., Flemming, J. P., Gino, A., \& Lauerman, R. (1978). Effects of alcohol on the storage and retrieval processes of heavy social drinkers. Journal of Experimental Psychology: Human Learning and Memory, 4, 246-255.

Moskowitz, H., \& Depry, D. (1968). Differential effect of alcohol on auditory vigilance and divided attention. Quarterly Journal of Studies on Alcohol, 29, 54-67.

Nelson, T. O., McSpadden, M., Fromme, K., and Marlatt, G. A. (1986). Effects of alcohol intoxication on metamemory and on retrieval from a long-term memory. Journal of Experimental Psychology: General,

Ostrom, T. M. (1984). The sovereignty of social cognition. In R. S. Wyer \& T. K. Srull (Eds.), Handbook of Social Cognition. Hillsdale, NJ: Erlbaum.

Rosen, L. J., \& Lee, C. L. (1976). Acute and chronic effects of alcohol use on organizational processes in memory. Journal of Abnormal Psychology, 85, 309-317.

Sanders, G. S., \& Suls, J. (1982). Social psychology of health and illness. Hillsdale, NJ: Erlbaum.

Schneider, W., Dumais, S. T. \& Shiffrin, R. M. (1984). Automatic and control processing and action. In R. Parasuraman \& D. R. Davies (Eds.), Varieties of attention. New York: Academic Press.

Steele, C. M., Critchlow, B., \& Liu, T. J. (1985). Alcohol and behavior: 2. The helpful drunkard. Journal of Personality and Social Psychology, 48, 35-46.

Steele, C. M. \& Josephs, R. A. (in press). Drinking your troubles away: 2. An attentionallocation model of alcohol's effect on psychological stress. Journal of Abnormal Psychology.

Steele, C. M., \& Southwick. L. (1985). Alcohol and social behavior: 1. The psychology of drunken excess. Journal of Personality and Social Psychology, 48, 18-34

Tabakoff, B., Sutker, P. B., \& Randall, C. L. (1983). Medical and social aspects of alcohol abuse. New York: Plenum.

Taylor, S. E., \& Brown, J. D. (1988). Illusion and well-being: A social-psychological perspective on mental health. Psychalogical Bulletin, 103, 193-210.

Tesser, A., \& Campbell, J. (1983). Self-definition and self-evaluation maintenance. In J. Suls \& A. G. Greenuald (Eds.), Psychological perspectives on the self (Vol. 2). Hillsdale. NJ: Erlbaum.

Thayer, B. A., \& Curtis, G. C. (1984). The effects of ethanol intoxication on phobic anxiety. Behaviour Research and Therapy, 22, 599-610.
Washburne, C. (1956). Alcohol, self, and the group. Quarterly Journal of Studies on Alcohol, 17, 108-123.

West, L. J. (1984). Alcoholism and related problems. In L. J. West (Ed.), Alcoholism and related problems: Issues for the American public. Englewood Cliffs, NI: Prentice-Hall.

Wicklund, R. A., \& Gollwitzer, P. M. (1982). Symbolic self-completion. Hillsdale, NJ: Erlbaum.

Wilson, G. T. (1978). Boozer, beliefs, and behavior: Cognitive factors in alcohol use and abuse. In P. E. Nathan, G. A. Marlatt, \& T. Loberg (Eds.), Alcoholism: New directions in behavioral research and treatment. New York: Plenum Press.

Wilson, G. T. (1983). Self-awareness, self-regulation, and alcohol consumption: An analysis of J. Hull's model. Journal of Abnormal Psychology.

Wilson, G. T., \& Abrams, D. B. (1977). Effects of alcohol on social anxiety and physiological anousal: Cognitive versus pharmacological processes. Cognitive Therapy and Research, 1, 195-210.

Wilson, G. T., Perold, E. A. \& Abrams, D. A. (1981). The effects of expectations of self-intoxication and partner's drinking on anxiety in dyadic social interaction. Cognitive Research and Therapy, 5, 251-264. 